\title{
Evaluasi Tingkat Efisiensi Penggunaan Energi Kajian Ex Post Facto Penerapan Standar Green Building Gedung A ITSB
}

\author{
Muhammad Arief Irfan ${ }^{1}$ \\ ${ }^{1}$ Staf Pengajar di Program Studi Arsitektur, ITSB. \\ e-mail: m.ariefirfan@gmail.com
}

\begin{abstract}
Abstrak
Di Indonesia, hingga tahun 2016, baru terdapat 11 unit Gedung yang berhasil tersertifikasi green building oleh Green Building Council Indonesia (GBCl). Kesebelas gedung tersebut merupakan gedung dengan klasifikasi new building dan diklaim efisien hingga $43 \%$. Isu efisiensi energi, dalam bangunan gedung semakin hari semakin menjadi wacana yang mulai dijadikan aksi riil.

Sebagai kampus pertama di Indonesia yang bersertifikasi green building dengan predikat gold, Gedung A Institut Teknologi dan Sains Bandung (ITSB) yang berlokasi di Cikarang, diharapkan menjadi gedung percontohan yang ramah lingkungan dan juga menjadi gedung yang mampu mencapai target efisiensi penggunaan energi. Gedung yang dimulai pembangunannya pada tahun 2009 dan selesai pada tahun 2011 ini, merupakan salah satu bangunan kategori new building yang sangat baik digunakan sebagai objek evaluasi. Sejak beroperasi pada tahun 2012, gedung ITSB belum pernah dilakukan kajian mengenai tingkat efisiensi dalam penggunaan energi. Riset dengan metode audit energi terhadap gedung ITSB, menunjukkan level efisiensi energi, khususnya penggunaan listrik, dalam periode tahun 2013 hingga tahun 2017. Dari data periode waktu tersebut, bisa dikaji mengenai kinerja bangunan peluang efisiensi energi di masa mendatang.
\end{abstract}

\begin{abstract}
In Indonesia, until 2016, there were only 11 building units that were successfully certified by green building by the Green Building Council Indonesia (GBCI). The eleven buildings are classified as new building and claimed to be $43 \%$ efficient. The issue of energy efficiency in buildings is increasingly becoming a real action.

As the first campus in Indonesia to be certified green building with the title of gold, Building A Bandung Institute of Technology and Science (ITSB), located in Cikarang, is expected to be an environmentally friendly pilot building and also a building capable of achieving energy efficiency targets. The building, which began construction in 2009 and completed in 2011, is one of the new building categories that is very well used as an evaluation object. Since its operation in 2012, the ITSB building has never been the object of study regarding the level of efficiency in energy use. The research carried out using the energy audit method for the ITSB building shows that there are levels of energy efficiency, especially electricity use, in the period of 2013 to 2017. From this period data, studies of building performance can be carried out with energy efficiency opportunities in the future. future.
\end{abstract}

Kata Kunci: efisiensi energi, audit energi, green building, SNI

\section{PENGANTAR}

Krisis energi yang bersumber dari fosil, memacu manusia untuk melakukan pengembangan dan efisiensi energi. Tidak ketinggalan juga peran profesi arsitek dalam menghemat penggunaan energi dalam bangunan. Di Indonesia, sejak tahun 1985, konservasi penggunaan energi terhadap bangunan sudah mulai diperkenalkan oleh Departemen Pekerjaan Umum (sekarang menjadi Kementrian Pekerjaan Umum) dengan program DOE (Department of Energy, Amerika Serikat). Pada tahun 1999, dibuatlah standar teknis konservasi energi yang selanjutnya 
Evaluasi Tingkat Efisiensi Penggunaan Energi

Kajian Ex Post Facto Penerapan Standar Green Building Gedung A ITSB

menjadi "SNI Prosedur Audit Energi". Dalam perkembangannya, Green Building Concept atau Konsep Bangunan Hijau, menjadi salah satu pilihan Arsitek dalam menjawab isu efisiensi energi. Berbagai standar green building dirumuskan agar mencapai titik efisiensi penggunaan energi secara optimal.

Kampus Institut Teknologi dan Sains Bandung (ITSB) yang berlokasi di Cikarang, merupakan gedung kampus pertama yang bersertifikasi green building di Indonesia. Sertifikasi dengan predikat gold dari Green Building Council Indonesia (GBCl) tersebut, diharapkan selain menjadi gedung percontohan yang ramah lingkungan, juga menjadi gedung yang mampu mencapai target efisiensi pengguna energi. Di Indonesia sendiri hingga tahun 2016, Gedung dengan klasifikasi new building, baru terdapat 11 unit yang berhasil disertifikasi oleh $\mathrm{GBCl}$, dan diklaim memiliki efisiensi rata-rata hingga $43 \%$.

Gedung ITSB ini, dimulai pembangunannya pada tahun 2009 dan selesai pada tahun 2011. Sebagai salah satu bangunan green building dengan kategori new building, gedung ini sangat baik digunakan sebagai objek riset karena mempertimbangkan berbagai kriteria dan aspekaspek green building sejak dalam proses perencanaan, pembangunan, operasional hingga perawatannya. Sejak beroperasi pada tahun 2012, belum pernah dilakukan kajian dan evaluasi mengenai tingkat efisiensi dalam penggunaan energi terhadap Gedung A ITSB. Riset ini bertujuan untuk mengkaji tingkat efisiensi penggunaan energi, yang salah satu metodenya adalah audit energi terhadap Gedung A ITSB dalam periode tahun 2013 hingga tahun 2017. Selain untuk menentukan kinerja green building terhadap aspek efisiensi energi, riset ini juga digunakan untuk membandingkan penggunaan energi dalam beberapa tahun untuk mencari variabel-variabel lain yang mempengaruhi fluktuasi penggunaan energi tersebut.

\section{Masalah Penelitian}

Terdapat beberapa kendala dan permasalahan dalam penelitian ini, antara lain:

1. Belum diperoleh data nyata mengenai penggunaan energi pada bangunanbangunan yang bersertifikasi green building.
2. Banyaknya variabel yang memberikan dampak pada penggunaan energi

\section{Batasan Penelitian}

Penelitian ini dibatasi pada tahapan Audit Energi Awal, Audit Energi Rinci, Analisis peluang penghematan meliputi perhitungan pola konsumsi energi di Gedung A ITSB dalam periode tahun 2013 hingga tahun 2017. Standar yang dipakai pada audit energi ini mengacu pada SNI 2011 (Standar Nasional Indonesia). Apabila Audit awal sudah menunjukan bahwa bangunan ini efisien, audit energi rinci dan tahap selanjutnya tidak akan dilakukan dan akan beralih pada analisa terhadap temuan-temuan lain.

\section{Tujuan Penelitian}

Tujuan dari penelitian ini adalah

1. Mengetahui tingkat efisiensi penggunaan energi pada bangunan ITSB

2. Menentukan IKE (Intensitas Konsumsi Energi) serta observasi penggunaan energi secara detail dan waktu penggunaannya.

3. Mengetahui peluang penghematan yang bisa dilakukan terhadap objek penelitian

\section{KAJIAN PUSTAKA}

\section{Green Building dan Efisiensi Energi}

Perubahan Iklim telah menyebabkan berbagai perubahan isu, terutama isu mengenai efisiensi energi dan pengalihan dari orientasi energi berbasis fosil menjadi energi terbarukan. Berbagai organisasi dunia juga berlomba untuk membuat kriteria maupun standart penilaian terhadap tingkat efisiensi energi. Sebut saja LEED, ENERGY STAR, Green Globes, dan National Green Building Standard, mencoba mendeskripsikan dan membuat sistem peringkat dalam efisiensi penggunaan energi. 


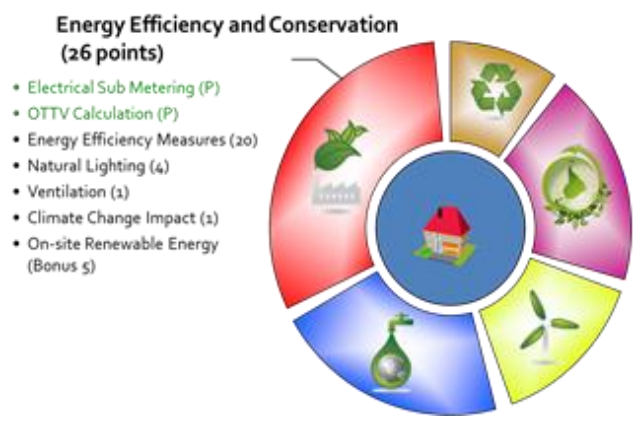

Gambar 1. Greenship Category (sumber GBCI)

Di Indonesia, $\mathrm{GBCl}$, merupakan salah satu organisasi yang melakukan standarisasi serta rating untuk bangunan-bangunan. Baik rumah tinggal hingga bangunan komersial. Terdapat 6 kategori dalam penilaian green building versi $\mathrm{GBCl}$, dan kategori penilaian terbesarnya adalah efisiensi energi dan konservasi. Dan dari kategori efisiensi energi dan konservasi tersebut, aspek terpenting yang menjadi standar $\mathrm{GBCl}$ adalah aspek pengukuran efisiensi energi, yang ditunjukan dengan poin penilaian terbanyak dibanding aspek yang lain.

\section{Audit Energi}

Banyak cara yang dapat dilakukan untuk mengevaluasi tingkat efisiensi energy, salah satunya adalah Audit Energi. Audit energi ini adalah dengan mengukur penggunaan energi pada bangunan eksisting atau bangunan yang telah beroperasi. Mengacu pada SNI 03-61962000 , audit ini memiliki prosedur dan metode.

Istilah audit sendiri lebih banyak digunakan pada sektor jasa keuangan atau finansial. Menurut Arens Loebbecke, pengertian audit adalah kegiatan mengumpulkan dan mengevaluasi dari bukti-bukti mengenai informasi untuk menentukan dan melaporkan tingkat kesesuaian antara informasi dengan kriteria yang telah ditetapkan dimana proses audit dilakukan oleh orang yang kompeten dan independen.

Sedangkan standar prosedur audit energi pada SNI 03-6196-2000, dimaksudkan sebagai pedoman bagi semua pihak yang terlibat dalam perencanaan, pelaksanaan, pengawasan dan pengelolaan bangunan gedung dalam rangka peningkatan efisiensi penggunaan energi dan menekan biaya energi. Audit Energi bertujuan mengetahui "Potret Penggunaan Energi" dan mencari upaya peningkatan efisiensi penggunaan energi.

\section{METODE}

Metode yang dilakukan adalah dengan audit energi. Audit energi dilakukan dengan urutan sebagai berikut:

\section{Audit Energi Awal}

Audit energi awal pada prinsipnya evaluasi yang didasarkan pada data $\mathrm{kWh}$ pada rekening pembayaran energi yang digunakan serta pengamatan visual. Kegiatan audit energi awal tidak memerlukan pengukuran. Data yang dibutuhkan tersebut meliputi :

A. Dokumentasi bangunan yang dibutuhkan adalah gambar teknik bangunan sesuai pelaksanaen konstruksi (as built drawing), terdiri dari gambar tapak, denah dan potongan bangunan gedung seluruh lantai, gambar denah instalasi pencahayaan bangunan seluruh lantai, serta diagram satu garis listrik, lengkap dengan penjelasan penggunaan daya listriknya dan besarnya penyambungan daya listrik PLN serta besarnya daya listrik cadangan dari Diesel Generating Set.

B. Untuk dapat mengaudit, dibutuhkan juga pembayaran rekening listrik bulanan bangunan gedung sejak tahun 2013 hingga tahun 2017.

\section{Audit Energi Rinci}

Audit energi rinci perlu dilakukan bila audit energi awal memberikan gambaran nilai IKE listrik lebih dari nilai target yang ditentukan. Audit ini perlu dilakukan untuk mengetahui profil penggunaan energi pada bangunan gedung, sehingga dapat diketahui peralatan pengguna energi apa saja yang pemakaian energinya cukup besar. Kegiatan yang dilakukan dalam penelitian energi adalah mengumpulkan dan meneliti sejumlah masukan yang dapat mempengaruhi besarnya kebutuhan energi bangunan gedung, dan dari hasil penelitian dan pengukuran energi dibuat profil penggunaan energi bangunan gedung.

Seluruh analisa energi bertumpu pada hasil pengukuran. Hasil pengukuran harus dapat 
Evaluasi Tingkat Efisiensi Penggunaan Energi

Kajian Ex Post Facto Penerapan Standar Green Building Gedung A ITSB

diandalkan dan mempunyai kesalahan (error) yang masih dapat diterima. Untuk itu penting menjamin bahwa alat ukur yang digunakan telah

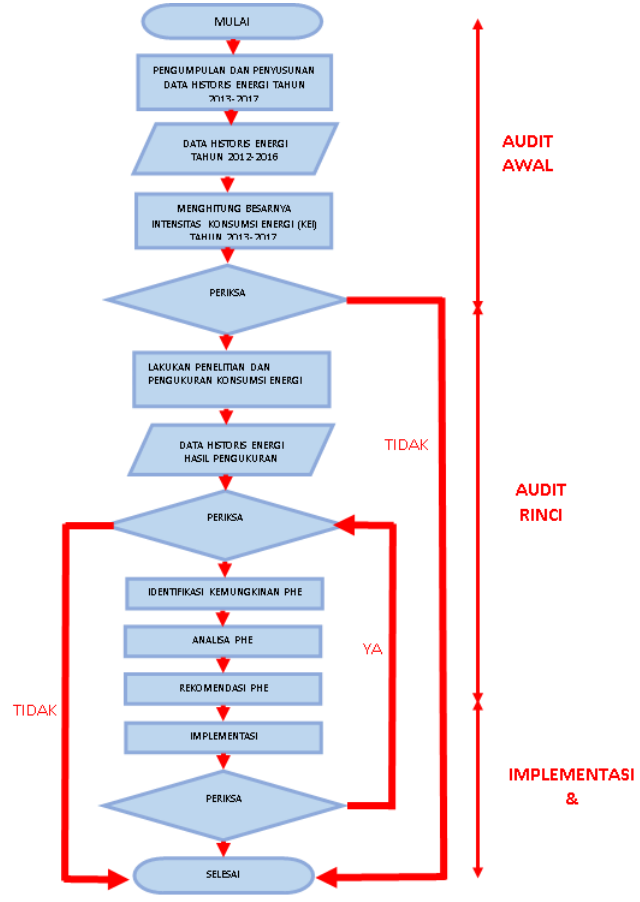

Gambar 2. Bagan alur proses audit energi. (sumber SNI 03-6196-2000)

dikalibrasi oleh instansi yang berwenang. Alat ukur yang digunakan dapat berupa alat ukur yang dipasang tetap (permanent) pada instalasi atau alat ukur yang dipasang tidak tetap (portable).

\section{Identifikasi Peluang Hemat Energi}

Hasil pengumpulan data pada proses audit rinci, selanjutnya ditindaklanjuti dengan penghitungan besarnya IKE dan penyusunan profil penggunaan energi bangunan gedung. Apabila besarnya IKE hasil penghitungan ternyata sama atau kurang dari IKE target, maka kegiatan audit energi rinci dapat dihentikan atau diteruskan untuk memperoleh IKE yang lebih rendah lagi. Bila hasilnya lebih dari IKE target, berarti ada peluang untuk melanjutkan proses audit energi rinci berikutnya guna memperoleh penghematan energi.

\section{Analisis peluang hemat energi}

Apabila peluang hemat energi telah diidentifikasi, selanjutnya perlu ditindak lanjuti dengan analisis peluang hemat energi, yaitu dengan cara membandingkan potensi perolehan hemat energi dengan biaya yang harus dibayar untuk pelaksanaan rencana penghematan energi yang direkomendasikan.

Analisis peluang hemat energi dapat juga dilakukan dengan penggunaan program komputer yang telah direncanakan untuk kepentingan itu dan diakui oleh masyarakat profesi. Penghematan energi pada bangunan gedung harus tetap memperhatikan kenyamanan penghuni.

\section{Intensitas Konsumsi Energi}

IKE adalah Istilah yang digunakan untuk menyatakan besarnya pemakaian energi listrik dalam bangunan gedung dan dinyatakan dalam satuan $\mathrm{KWh} / \mathrm{m} 2$. Terdapat perbedaan kriteria dalam standar efisiensi energi antara gedung yang menggunakan Air Conditioner (AC) dan gedung tidak menggunakan $\mathrm{AC}$, seperti terlihat dalam tabel 1. Dan tabel 2.

Tabel 1. IKE Bangunan Gedung Tidak ber-AC

\begin{tabular}{|c|c|}
\hline Kriteria & Keterangan \\
\hline $\begin{array}{c}\text { Efisien } \\
(10-20) \\
\mathrm{kWh} / \mathrm{m}^{2} / \text { Tahun }\end{array}$ & $\begin{array}{l}\text { a) Pengelolaan gedung dan } \\
\text { peralatan energi dilakukan } \\
\text { dengan prinsip konfersi } \\
\text { energi listrik } \\
\text { b) Pemeliharaan peralatan } \\
\text { energi dilakukan sesuai } \\
\text { dengan prosedur } \\
\text { c) Efisiensi pengguanaan } \\
\text { energi masih mungkin } \\
\text { ditingkatkan melalui } \\
\text { penerapan sistem } \\
\text { manajemen energi }\end{array}$ \\
\hline $\begin{array}{l}\text { Cukup Efisien } \\
(20-30) \\
\text { kWh/m2/Tahun }\end{array}$ & $\begin{array}{l}\text { a) Penggunaan energi cukup } \\
\text { efisien namun masih } \\
\text { memiliki peluang konservasi } \\
\text { energi } \\
\text { b) b) Perbaikan efisiensi } \\
\text { melalui pemeliharaan } \\
\text { bangunan dan peralatan } \\
\text { energi masih dimungkinkan }\end{array}$ \\
\hline $\begin{array}{c}\text { Boros } \\
(30-40) \\
\mathrm{kWh} / \mathrm{m} 2 / \text { Tahun }\end{array}$ & $\begin{array}{l}\text { a) Audit energi perlu dilakukan } \\
\text { untuk menentukan langkah- } \\
\text { langkah perbaikan sehingga } \\
\text { pemborosan energi dapat } \\
\text { dihindari } \\
\text { b) Desain bangunan maupun } \\
\text { pemeliharaan dan }\end{array}$ \\
\hline
\end{tabular}




\begin{tabular}{|c|c|c|}
\hline & & $\begin{array}{l}\text { pengoperasian gedung } \\
\text { belum mempertimbangkan } \\
\text { konservasi energi }\end{array}$ \\
\hline \multirow{3}{*}{$\begin{array}{l}\text { Sangat Boros } \\
(40-50) \\
\text { kWh/m2/Tahun }\end{array}$} & a) & $\begin{array}{l}\text { Instalasi peralatan, desain } \\
\text { pengoperasian dan } \\
\text { pemeliharaan tidak } \\
\text { mengacu pada } \\
\text { penghematan enerai }\end{array}$ \\
\hline & b) & $\begin{array}{l}\text { Agar dilakukan peninjauan } \\
\text { ulang atas semua instalasi } \\
\text { /peralatan energi serta } \\
\text { penerapan managemen } \\
\text { energi dalam pengelolaan } \\
\text { bangunan }\end{array}$ \\
\hline & c) & $\begin{array}{l}\text { Audit energi adalah langkah } \\
\text { awal yang perlu dilakukan }\end{array}$ \\
\hline
\end{tabular}

Tabel 2. IKE Bangunan Gedung ber-AC

\begin{tabular}{|c|c|}
\hline Kriteria & Keterangan \\
\hline $\begin{array}{c}\text { Sangat Efisien } \\
(50-95) \\
\text { kWh/m2/Tahun }\end{array}$ & $\begin{array}{l}\text { a) Desain gedung sesuai } \\
\text { standar tatacara } \\
\text { perencanaan teknis } \\
\text { konservasi energi } \\
\text { b) Pengoperasian peralatan } \\
\text { energi dilakukan dengan } \\
\text { prinsip-prinsip menejemen } \\
\text { energi }\end{array}$ \\
\hline $\begin{array}{c}\text { Efisien } \\
(95-145) \\
\text { kWh/m2/Tahun }\end{array}$ & $\begin{array}{l}\text { a) Pemeliharaan gedung dan } \\
\text { peralatan energi dilakukan } \\
\text { sesuai prosedur } \\
\text { b) Efisiensi penggunaan energi } \\
\text { masih mungkin ditingkatkan } \\
\text { melalui penerapan sistem } \\
\text { menejemen energi terpadu }\end{array}$ \\
\hline $\begin{array}{l}\text { Cukup Efisien } \\
(95-145) \\
\text { kWh/m2/Tahun }\end{array}$ & $\begin{array}{l}\text { a) Penggunaan energi cukup } \\
\text { efisien melalui } \\
\text { pemeliharaan bangunan } \\
\text { dan peralatan energi masih } \\
\text { memungkinkan } \\
\text { b) Pengoperasian dan } \\
\text { pemeliharaan gedung } \\
\text { belum mempertimbangkan } \\
\text { prinsip konservasi energi }\end{array}$ \\
\hline $\begin{array}{c}\text { Agak Boros } \\
(145-175) \\
\text { kWh/m2/Tahun }\end{array}$ & 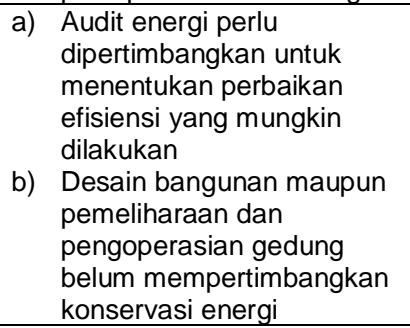 \\
\hline $\begin{array}{c}\text { Boros } \\
(175-285) \\
\text { kWh/m2/Tahun }\end{array}$ & $\begin{array}{l}\text { Audit energi perlu } \\
\text { dipertimbangkan untuk } \\
\text { menentukan langkah- } \\
\text { langkah perbaikan sehingga } \\
\text { pemborosan energi dapat } \\
\text { dihindari }\end{array}$ \\
\hline
\end{tabular}

\begin{tabular}{|c|c|}
\hline Kriteria & Keterangan \\
\hline & $\begin{array}{l}\text { b) Instalasi peralatan dan } \\
\text { desain pengoperasian dan } \\
\text { pemeliharaan tidak } \\
\text { mengacu pada } \\
\text { penghematan energi }\end{array}$ \\
\hline $\begin{array}{c}\text { Sangat Boros } \\
(285-450) \\
\text { kWh/m2/Tahun }\end{array}$ & $\begin{array}{l}\text { a) Agar ditinjau ulang atas } \\
\text { semua instalasi /peralatan } \\
\text { energi serta penerapan } \\
\text { menejemen energi dalam } \\
\text { pengelolan bangunan } \\
\text { b) b) Audit energi adalah } \\
\text { langkah awal yang perlu } \\
\text { dilakukan }\end{array}$ \\
\hline
\end{tabular}

\section{DATA EKSISTING GEDUNG A ITSB}

Keuntungan desain dengan standar green building adalah rencana elektrikalnya yang cukup rapi dan terpisah antar lantai, antar peralatan dan antar fungsi. Sehingga bisa identifikasi penggunaan energi listrik dapat dianalisa dengan baik karena terpartisi penggunaannya.

\begin{tabular}{|c|c|c|c|c|}
\hline T? & 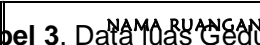 & $\frac{\text { LUAS }}{3\left(\mathrm{~m}^{2}\right)}$ & KOEFISIEN & \begin{tabular}{|c|} 
TOTAL LUAS \\
$\left(\mathrm{m}^{2}\right)$
\end{tabular} \\
\hline \multicolumn{5}{|c|}{ LANTAI SATU } \\
\hline 11 & TERAS DEPAN & 35.90 & $100 \%$ & 35.90 \\
\hline 2 & LOBBY UTAMA & 15.08 & $100 \%$ & 15.08 \\
\hline 3 & MARKETINC GALLERY & 76.00 & $100 \%$ & 76.00 \\
\hline 4 & R. PELATIHAN & 72.03 & $100 \%$ & 72.03 \\
\hline 5 & R. LPPM & 72.03 & $100 \%$ & 72.03 \\
\hline 6 & R. AKADEMIK \& BANK & 72.03 & $100 \%$ & 72.03 \\
\hline 7 & R. TUNGGU & 73.74 & $100 \%$ & 73.74 \\
\hline 8 & R. HIMPUNAN & 47.94 & $100 \%$ & 47.94 \\
\hline 9 & MUSHOLLA \& WUDLU & 53.32 & $100 \%$ & 53.32 \\
\hline 10 & KANTIN \& KORIDOR & 176.63 & $100 \%$ & 176.63 \\
\hline 11 & KORIDOR TERBUKA & 184.76 & $100 \%$ & 184.76 \\
\hline 12 & LIFT, TOILET \& SERVICE & 75.24 & $100 \%$ & 75.24 \\
\hline 13 & TANGGA UTAMA & 38.74 & $100 \%$ & 38.74 \\
\hline 14 & KOLONG BANGUNAN (KANTIN) & 66.30 & $50 \%$ & 33.15 \\
\hline \multirow{2}{*}{\multicolumn{4}{|c|}{ TOTAL LANTAI SATU }} & 10765 \\
\hline \multirow{2}{*}{\multicolumn{4}{|c|}{ LANTAI DUA }} & \\
\hline & & & $100 \%$ & $\overline{64.62}$ \\
\hline 2 & R. ZAT \& ALAT & 14.13 & $100 \%$ & 14.13 \\
\hline 3 & LAB. KIMIA DASAR & 72.03 & $100 \%$ & 72.03 \\
\hline 4 & LAB. FISIKA DASAR & 72.03 & $100 \%$ & 72.03 \\
\hline 5 & LAB. BAHASA & 72.03 & $100 \%$ & 72.03 \\
\hline 6 & LAB. KOMPUTER & 72.03 & $100 \%$ & 72.03 \\
\hline 7 & R. SERVER & 12.60 & $100 \%$ & 12.60 \\
\hline 8 & REKTORAT \& R. DOSEN & 525.33 & $100 \%$ & 525.33 \\
\hline 9 & KORIDOR TERBUKA & 96.57 & $100 \%$ & 96.57 \\
\hline 10 & TANGA UTAMA & 38.74 & $100 \%$ & 38.74 \\
\hline 11 & LIFT, TOILET \& SERVICE & 73.71 & $100 \%$ & 73.71 \\
\hline 12 & KANOPI DEPAN & 271.50 & $0 \%$ & 0.00 \\
\hline 13 & KANOPI SAMPING & 114.50 & $0 \%$ & 0.00 \\
\hline \multicolumn{4}{|c|}{ TOTAL LANTAI DUA } & 1113.82 \\
\hline
\end{tabular}


Evaluasi Tingkat Efisiensi Penggunaan Energi

Kajian Ex Post Facto Penerapan Standar Green Building Gedung A ITSB

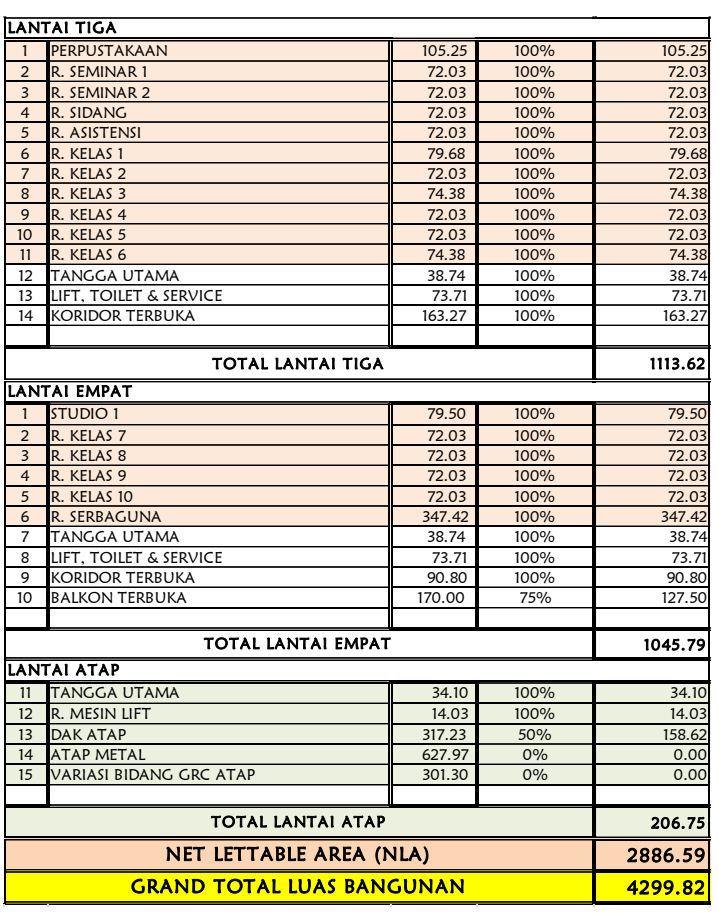

Berikut ini skema pembagian meteran listrik dalam Gedung A ITSB.

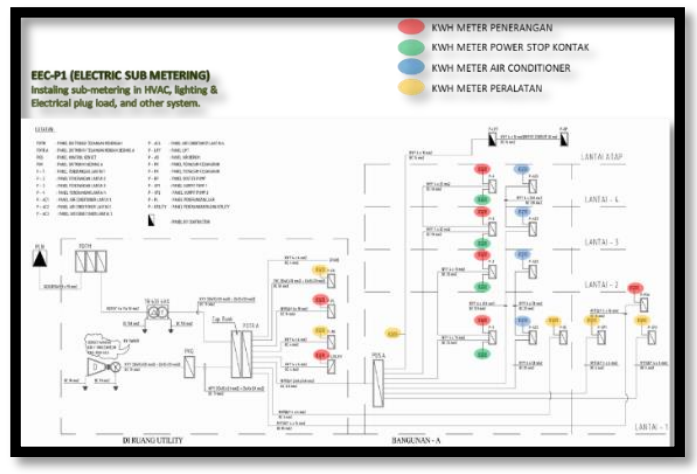

Gambar 3. Intalasi Elektrikal Gedung A ITSB

Gambar 3. menunjukan bahwa, desain elektrikal Gedung A ITSB cukup baik. Dengan adanya kWh meter terpisah, didapatkan data yang rinci per pembagian instalasi dan juga per-lantai bangungan. Selain itu, data pencatatan harian kWh yang digunakan bangunan ini, dilakukan dengan baik.

Dari data pencatatan penggunaan listrik harian di Gedung A ITSB, dapat dirangkum data tersebut menjadi data penggunaan listrik pertahun.

Dari data penggunaan listrik pada Tabel 4. dan luas bangunan pada Tabel 3 , bisa diperoleh angka IKE seperti yang dapat dilihat pada Tabel 5. Tabel 5. menunjukan bahwa seluruh bagian dalam Gedung A ITSB memiliki indikator efisiensi penggunaan listrik yang cukup baik. Rata-rata penggunaan listrik tertinggi terdapat pada tahun 2016 dan lebih spesifik di lantai III dengan nilai IKE 78,11. Nilai tertinggi ini masih berada dalam batas standar sangat efisien bangunan yang menggunakan AC yaitu antara 50-95 kWh/m²/tahun. Dengan nilai IKE yang sudah terpenuhi (efisien), audit awal ini dinyatakan cukup, sehingga tidak perlu dilakukan prosedur lebih lanjut (audit rinci).

Tabel 4. Rangkuman Penggunaan kWh per-Tahun pada Gedung A ITSB

\begin{tabular}{|l|l|l|l|l|l|}
\hline kWh Meter & 2013 & 2014 & 2015 & 2016 & 2017 \\
\hline
\end{tabular}




\begin{tabular}{|c|r|r|r|r|r|}
\hline LANTAI I & 44322,31 & 46245,00 & 44996,40 & 47785,64 & 45815,39 \\
\hline LANTAI II & 34567,09 & 25482,27 & 77939,98 & 63617,06 & 61695,68 \\
\hline LANTAI III & 24138,31 & 24828,87 & 51410,01 & 86986,58 & 78926,74 \\
\hline LANTAI IV & 24412,88 & 23445,47 & 48022,84 & 59995,01 & 58056,62 \\
\hline
\end{tabular}

Tabel 5. IKE per-Tahun pada Gedung A ITSB

\begin{tabular}{|c|c|c|c|c|c|}
\hline IKE Tahun Penggunaan & 2013 & 2014 & 2015 & 2016 & 2017 \\
\hline LANTAI I & 43,17 & 45,05 & 43,83 & 46,55 & 44,63 \\
\hline LANTAI II & 31,03 & 22,88 & 69,98 & 57,12 & 55,39 \\
\hline LANTAI III & 21,68 & 22,30 & 46,16 & 78,11 & 70,87 \\
\hline LANTAI IV & 23,34 & 22,42 & 45,92 & 57,37 & 55,51 \\
\hline
\end{tabular}

\section{DISKUSI}

Pembahasan berikutnya justru ditujukan untuk membuat hipotesa terhadap temuan-temuan terhadap data-data tersebut. Hal ini ditujukan juga untuk dilakukannya pengembanganpengembangan riset yang lanjutan yang lain. Beberapa temuan yang menarik adalah adanya peningkatan drastis penggunaan listrik yaitu sekitar $85 \%$ pada tahun 2015 dan puncaknya pada tahun 2016 dengan kenaikan 16\% dibanding tahun sebelumnya. (lihat gambar 4.) 


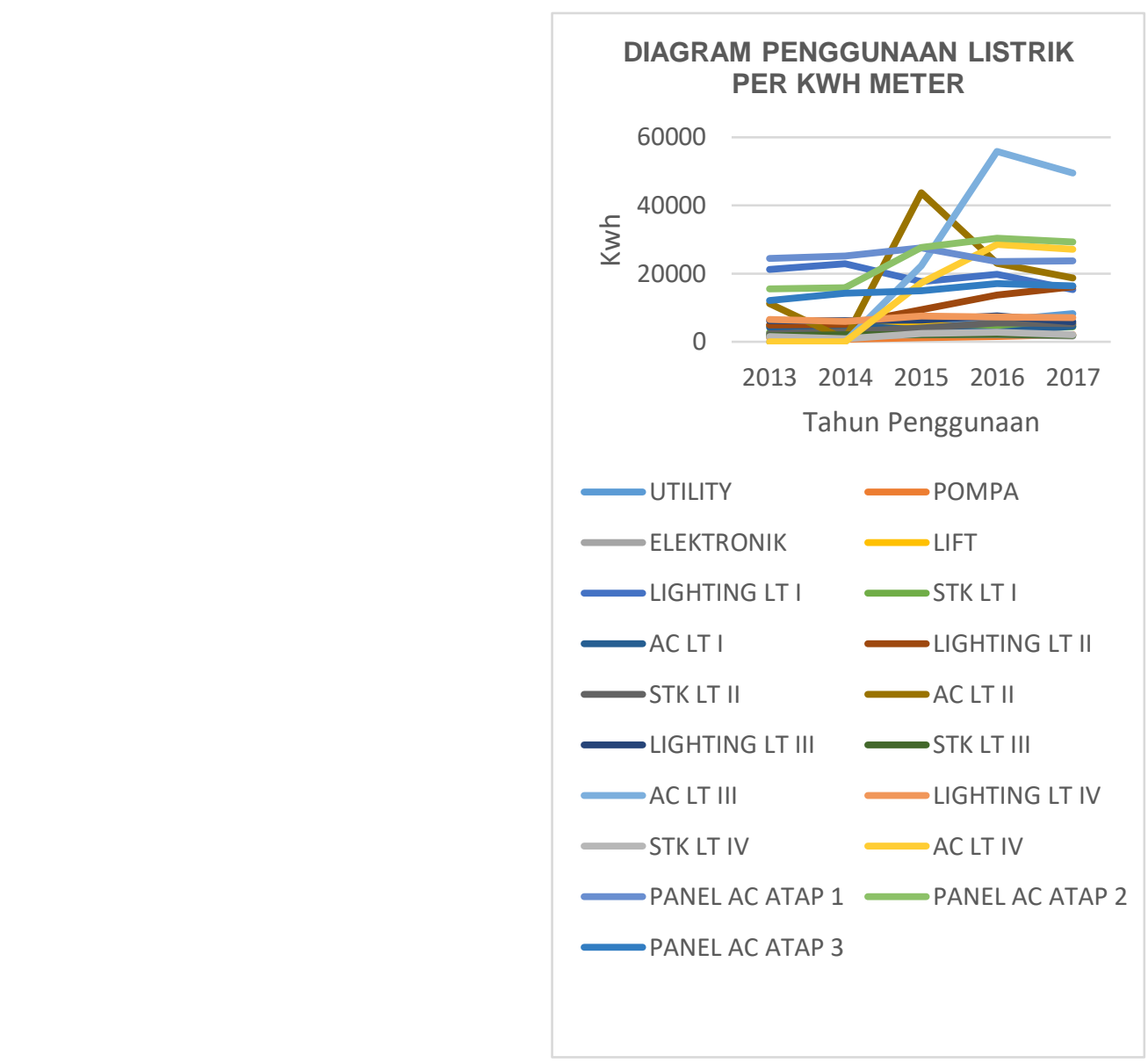

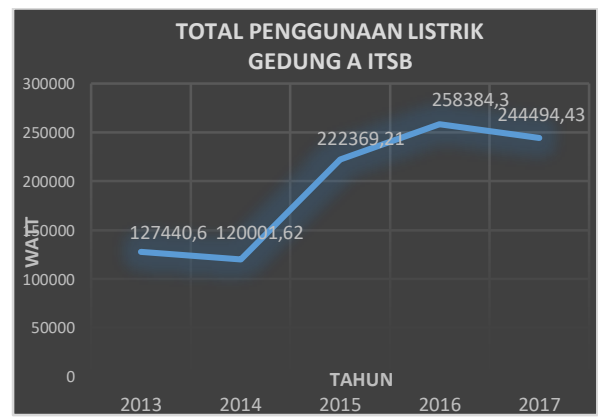

Gambar 4. Total penggunaan listrik Gedung A ITSB

Dari data (Gambar 4.) tersebut, kemudian dilakukan pemisahan data berdasarkan pengelompokan-pengelompokan kWh meter. Dari pemisahan tersebut, diperoleh hasil bahwa penggunaan AC pada lantai II, III dan IV. (lihat Gambar 5.) Sedangkan penggunaan AC pada lantai I masih relatif setabil. Banyak hipoesa baru yang bisa dimunculkan dari data-data tersebut. Salah satunya adalah kemungkinan penggunaan ruang kelas dan ruang laboratorium yang semakin tinggi intensitasnya. Hal ini dikarenakan lantai II,III dan IV adalah ruang-ruang yang didominasi oleh ruang perkuliahan dan juga laboratorium. Data tersebut juga bisa dibuat hipotesa yang lain yaitu belum adanya kesadaran penggunanya (user) terhadap green habits atau kebiasaan untuk efisien dalam penggunaan listrik. Sejak awal beroperasi, civitas akademika di ITSB belum pernah mendapatkan pelatihan maupun training mengenai hal tersebut. 


\section{KESIMPULAN}

Hasil pengukuran pada Gedung A ITSB menunjukan konsumsi listrik di bawah 80 $\mathrm{kWh} / \mathrm{m} 2 /$ tahun atau dalam sandar sangat efisien. Penelitian ini berhasil membuktikan bahwa bangunan dengan standar green building, khususnya pada Gedung A ITSB, mampu mereduksi penggunaan energi listrik. Meskipun begitu, penggunaan listrik di Gedung $A$ ITSB menunjukan adanya peningkatan konsumsi. Hal ini nantinya bisa menjadi bahan kajian baru untuk mendapatkan berbagai variabel yang menyebabkan naiknya konsumsi tersebut.

\section{DAFTAR PUSTAKA}

Andamon M.M. 2006. Thermal Comfort and Building Energy Consumption in the Philippine Context: the 23 Conference on Passive and Low Energy Architecture, Geneva, Switzerland, 6-8 September.

Arens Loebbecke. 1999. Auditing Pendekatan Terbaru, Edisi kedua. Jakarta: Salemba, Empat.

Badan Standarisasi Nasional. 2005. Prosedur Audit Energi pada Bangunan Gedung, Konservasi Energi Sistem Tata Udara pada Bangunan Gedung dan Konservasi Energi Sistem Pencahayaan Bangunan Gedung. Jakarta.

De Dear, R. \& Brager, G.S. 1998. Thermal Adaptation in the Built Environment: $A$ Literature Review. Energy and Building, 27, 83-96.

Johnson Stuart. 1993. Greener Buildings: Environmental Impact of Property, London: Macmillan Press. Ltd.

Khisnani Nirmal. 2012. Greening Asia: Emerging Principles for Sustainable Architecture. Singapore: BCI Asia.

Moore, G.T. 1979. Environment and Behaviour Studies. In J.C. Snyder \& A.J. Catanese (Eds.) Introduction to Architecture New York: McGraw-Hill, 4671.

Reeder Linda. 2010. Guide to Green Building Rating System: Understanding
LEED, Green Globe, ENERGY STAR, The National Green Building Standard, and More. New Jersey: John Willey \& Sons, Inc.

SNI 04-0225-2000/amd.1-2006. Standar Nasional Indonesia, tentang Persyaratan Umum Instalasi Listrik 2000 (puil 2000) di tempat kerja. Jakarta.

SNI 03-6389-2000. Standar Nasional Indonesia, tentang Konservasi Energi Selubung Bangunan Pada Bangunan Gedung. Jakarta.

SNI 03-6197-2011. Standar Nasional Indonesia, tentang Konservasi Energi pada Sistem Pencahayaan. Jakarta.

SNI 03-6196-2000. Standar Nasional Indonesia, tentang Prosedur audit energi pada bagunan gedung. Jakarta.

Untoro Jati, Gusmedi Herri, Purwasih Nining. Jurnal Rekayasan dan Teknologi Elektro Vol. 8, No. 2, Mei 2014: Audit Energi dan Analisis Penghematan Konsumsi Energi pada Sistem Peralatan Listrik di Gedung Pelayanan Unila. Lampung.

Yeang Ken. 1999. The Green Skyscraper: The Basis for Designing Sustainable Inensive Buildings. London: Prestel 